\title{
Research on the Source Structure Evolution of Inbound Tourism in Hainan Province Based on the Shift Share Method*
}

\author{
Fuyuan Bao \\ International Hospitality Management School \\ University of Sanya \\ Sanya, China 572022
}

\begin{abstract}
The source structure evolution is an important part of researches on the development of inbound tourism market. The source structure evolution of inbound tourism in Hainan Province during different periods in 2008-2015 is analyzed by using SSM. It is found that the advantage and competitiveness of inbound tourist source structure in Hainan in 2008-2009 were severely weakened, and the development level was far lower than the national average; the advantage and competitiveness of the inbound tourist source structure in Hainan in 2009-2012 rebounded greatly; however, in 2012-2015, the advantage and competitiveness of the inbound tourist source structure in Hainan decreased significantly again. For the inbound tourist of Hainan, there are major fluctuations in the scale of tourists from major tourist generating regions. It is suggested that measures be taken to ensure the stability of dominant tourist sources, enhance the specific development of traditional major tourist sources, improve the provision of tourism services and enhance internationalization level, to attract more tourists from Europe and North America.
\end{abstract}

Keywords—inbound tourism; source structure; SSM

\section{INTRODUCTION}

The global financial crisis triggered by the US subprime crisis has caused a sharp decline in inbound tourism markets of many countries, and the inbound tourism market in China has also suffered adverse effects. Inbound tourism in many major tourism provinces in China is facing a shrinking trend. Among them, Hainan is a comprehensive experimental zone for the development and reform of tourism industry in China. The international tourism island strategy has injected new impetus for the social and economic development of Hainan, but the global economic downturn has also had a huge impact on inbound tourism of Hainan. The official data released by Hainan Tourism Department shows that the scale of inbound tourism in Hainan has dropped significantly since 2008-2009, which basically stabilized in 2010 and started to pick up, but declined again in 2012, and upswung in 2016 after stabilized in 2015. During this period, 2010 and 2015 were the lowest points in recent years, and 2012 was the intermediate high point. Inbound tourism in Hainan basically showed a "W"shaped evolution, and the inbound tourism data of China and Hainan are shown in "Fig. 1".

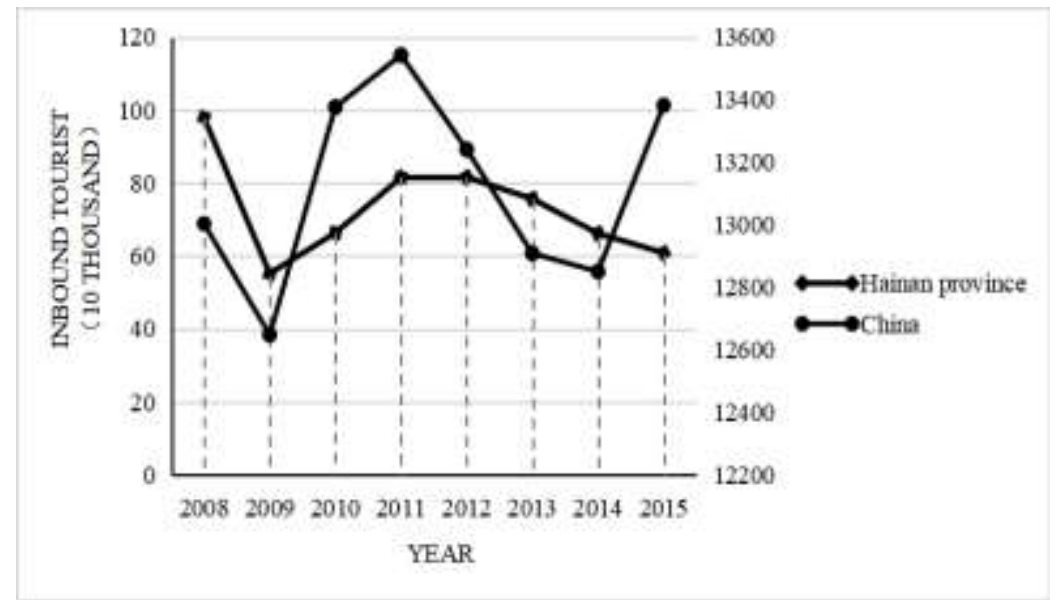

Fig. 1. Data change of inbound tourism in China and Hainan Province, 2008-2015. (Source: Official Website of Hainan Provincial Tourism Commission, China

*Fund Project: Science Research Project of Colleges and Universities in Hainan Province, Research on Spatial-temporal Structure, Influencing Factors and Precise Development of Inbound Tourism in Hainan (No. Hnky 2018-64) CLC number: F590 Tourism Statistics Yearbook)

Researching the source structure evolution of inbound tourism in Hainan and analyzing the market situation of 
inbound tourist sources can help identify the dominant tourist sources and effectively carry out market promotion. The SSM (Shift Share Method, hereinafter referred to as SSM) has been maturely applied in the analysis of source structure evolution in tourism. Macroscopically, FANG Yelin (2016) analyzed the evolution of spatial-temporal pattern of China's inbound tourism industry structure and its types[1], and most of the researches focus on specific provinces, for example, HUANG Xiujuan (2004) divided the overseas tourist source markets of Fujian Province into four types based on SSM: prosperity, rise, decline, and stagnation[2]; LV Shuai (2006), ZHOU Caiping (2008), CUI Feng (2008), WANG Li (2011), SHI Dan (2010) took Shanghai, Zhejiang, Jiangsu, Liaoning and Jilin as examples, and used SSM to research the inbound tourist source structure[3][4][5][6][7]. Analysis of inbound tourism in Hainan based on SSM has been initially carried out. SU Peng (2010) researched 14 tourist sources of inbound tourism in Hainan in 2004-2007 and found that the growth rate of inbound tourism in Hainan was higher than the national average, and there was a large proportion of markets with high-speed growth[8]; some researchers took provinces in the Pan-Pearl River Delta region as upper-level regions, and compared the competitive situation in inbound tourism of Hainan among them[9], but the period data of these researches are relatively old and the number of tourist sources is relatively small. Therefore, this paper selects the inbound tourism data of Hainan in 2008-2016, analyzes the inbound tourist source structure in Hainan based on SSM, and divides the 26 tourist sources to define the emphases of future development.

\section{BASIC PRINCIPLES AND MODEL CONSTRUCTION OF ANALYSIS BASED ON SSM}

\section{A. Basic Principle}

SSM is relatively common in the analysis of regional and urban economic structures abroad. In the 1990s, this method was widely adopted by scholars in China, but it was mostly limited to the analysis of the three major industrial structures and industrial competitiveness, and there was few research on the internal structure of individual industries[5]. Analysis based on SSM regards regional economic evolution as a dynamic process, takes the economic development of the higher-level region where it is located as reference, and decomposes the total amount of evolution of its own economy in a certain period into share components, structure shift components, and competitiveness shift components, to explain the reasons for regional economic development or recession, evaluate the strengths, weaknesses and competitiveness of the regional economic structure, and explore sectors or regions with comparative advantages[6]. In recent years, this method has been applied in tourism, mainly to research and determine the direction of optimization and adjustment of future tourism economic structure. Researches on the inbound tourist source structure have gradually increased, and the advantages of this method have been proved. In this paper, SSM is used and the national inbound tourism is taken as reference to compare the source structure evolution of inbound tourism in Hainan, grasp the evolution trend of the inbound tourism source in Hainan, and provide theoretical guidance for optimizing the inbound tourist source structure in Hainan and improving the competitiveness of inbound tourism.

\section{B. Model Construction}

According to the basic principle of SSM, it is assumed that both the tourist volume and structure of tourist province $i$ changed after period $[0, t]$. It is set that $a_{i j, 0}$ is the number of inbound tourists from the source $\mathrm{j}$ to province $\mathrm{i}$ in the base period and $a_{i j, t}$ is the number of inbound tourists from the source $\mathrm{j}$ to province $\mathrm{i}$ in the final period. $\mathrm{A}_{\mathrm{j}, 0}$ is the total number of inbound tourists from the source $j$ to the country of tourist destination in the base period, and $\mathrm{A}_{\mathrm{j}, \mathrm{t}}$ is the total number of inbound tourists from the source $\mathrm{j}$ to the country of tourist destination in the final period.The rate of change in inbound tourist flow from the source $\mathrm{j}$ to the tourist province $\mathrm{i}$ during period $t$ is:

$$
\mathrm{r}_{i j}=\left(a_{i j, t}-a_{i j, 0}\right) / a_{i j, o}(1)
$$

The rate of change in the number of inbound tourists from the source $\mathrm{j}$ to the country of tourist destination during period $\mathrm{t}$ is:

$$
\mathrm{R}_{j}=\left(A_{j, t}-A_{j, 0}\right) / A_{j, 0}(2)
$$

Based on the proportion of tourist flow in each source of the country during the base period, the tourist flow of each source in province $i$ will be standardized as the following formula:

$$
\mathrm{a}_{\mathrm{ij}}{ }^{\prime}=a_{j, 0} \times\left(A_{j, 0} / A_{0}\right)(3)
$$

In formula (3), $\mathrm{A}_{0}$ is the total number of inbound tourists in the country in the base period, $\mathrm{A}_{\mathrm{j}, 0}$ is the total number of inbound tourists from the source $\mathrm{j}$ to our country in the base period, $a_{i, 0}$ is the total number of inbound tourists in province $i$ in the base period, and $a_{i j}{ }^{\prime}$ is the total number of inbound tourists from source $\mathrm{j}$ to province $\mathrm{i}$ after standardization.

The increment $G_{i j}$ of the number of inbound tourists from source $\mathrm{j}$ to province $\mathrm{i}$ in the period $[0, \mathrm{t}]$ can be decomposed into the share component $\mathrm{N}_{\mathrm{ij}}$, the structure shift component $\mathrm{P}_{\mathrm{ij}}$ and the competitiveness shift component $\mathrm{D}_{\mathrm{ij}}$, as follows:

$$
\mathrm{G}_{i j}=a_{i j, t}-a_{i j, 0}=N_{i j}+P_{i j}+D_{i j}
$$

It is set in Formula (4) that:

$$
\begin{aligned}
& \mathrm{N}_{i j}=a_{i j}{ }^{\prime} \times R_{j}(5) \\
& P_{i j}=\left(a_{i j, 0}-a_{i j}{ }^{\prime}\right) \times R_{j}(6) \\
& \mathrm{D}_{i j}=a_{i j, 0} \times\left(r_{i j}-R_{j}\right)
\end{aligned}
$$

In formula (4), $\mathrm{N}_{\mathrm{ij}}$ is the change in the tourist flow of each province's standardized source according to the average growth rate of inbound tourism in the country; $P_{i j}$ is the structural effect of the source market, which refers to the shift between the growth of each source in each province and the whole country caused by the difference between the proportion of each province's source markets and the proportion of the corresponding national market, which excludes the difference between the growth rate of each province and the national average speed, and assuming the two rate are equivalent, the impact and contribution of the source market structure to the 
growth is analyzed independently, the larger the value, the greater contribution of the source structure to the total tourist flow; $D_{i j}$ is the effect of regional share, which refers to the shift caused by the difference between the growth rate of each tourist source in each province and the growth rate of the corresponding national tourist market, and reflects the relative competitiveness of each source country, and the greater the value, the greater the effect of the competitiveness of a tourist source in each province on the growth of tourist sources.

Taking Hainan Province as an example, $G_{i}$ is set as the total inbound tourist increment of inbound tourism in Hainan during the period $[0, \mathrm{t}], \mathrm{N}_{\mathrm{i}}$ is set as the total share component, $\mathrm{P}_{\mathrm{i}}$ is the total structural shift component, and $\mathrm{D}_{\mathrm{i}}$ is the total competitiveness shift component. Among them,

$$
\begin{aligned}
G_{i} & =a_{i, t}-a_{i, 0}=N_{i}+P_{i}+D_{i} \\
\mathrm{~N}_{i} & =\sum a_{i j}{ }^{\prime} \times R_{j}(9) \\
\mathrm{P}_{i} & =\sum\left(a_{i j, 0}-a_{i j}{ }^{\prime}\right) \times \mathrm{R}_{j}(10) \\
D_{i} & =\sum a_{i j, 0} \times\left(r_{i j}-R_{j}\right)_{(11)}
\end{aligned}
$$

$a_{i, t}$ is the total number of inbound tourists in Hainan in the final period. $a_{i, 0}$ is the total number of inbound tourists in Hainan in the base period. The relative growth rate of inbound tourists in province $\mathrm{i}$ to the whole country is:

$$
\mathrm{L}=\left(\sum a_{j, t} / \sum a_{j, 0}\right) /\left(A_{t} / A_{0}\right)
$$

Introducing:

TABLE I. NUMBER OF TOURISTS OF INBOUND TOURISM IN HAINAN PROVINCE FROM EACH TOURIST SOURCE IN 2008-2015

\begin{tabular}{lllllllll}
\hline Pear & $\mathbf{2 0 0 8}$ & $\mathbf{2 0 0 9}$ & $\mathbf{2 0 1 0}$ & $\mathbf{2 0 1 1}$ & $\mathbf{2 0 1 2}$ & $\mathbf{2 0 1 3}$ & $\mathbf{2 0 1 4}$ & $\mathbf{2 0 1 5}$ \\
\hline Japan & 3.670 & 2.748 & 2.479 & 2.134 & 1.697 & 1.101 & 0.993 & 1.000 \\
\hline South Korea & 12.713 & 2.381 & 3.174 & 2.622 & 1.605 & 2.736 & 1.825 & 3.850 \\
\hline North Korea & 0.170 & 0.215 & 0.037 & 0.042 & 0.071 & 0.104 & 0.069 & 0.085 \\
\hline Mongolian & 0.038 & 0.057 & 0.092 & 0.146 & 0.210 & 0.324 & 0.267 & 0.292 \\
\hline Philippines & 0.185 & 0.163 & 0.303 & 0.452 & 0.256 & 0.251 & 0.175 & 0.217 \\
\hline Thailand & 0.560 & 0.332 & 0.505 & 0.619 & 0.729 & 0.710 & 0.547 & 0.804 \\
\hline Singapore & 3.401 & 2.782 & 4.756 & 5.908 & 6.945 & 4.479 & 3.960 & 3.395 \\
\hline Indonesia & 0.283 & 0.281 & 0.390 & 0.609 & 0.771 & 0.510 & 0.648 & 0.431 \\
\hline Malaysia & 3.317 & 2.163 & 2.754 & 2.220 & 2.662 & 2.559 & 2.240 & 1.831 \\
\hline Pakistan & 0.023 & 0.022 & 0.021 & 0.022 & 0.032 & 0.045 & 0.073 & 0.040 \\
\hline India & 0.230 & 0.149 & 0.242 & 0.408 & 0.226 & 0.170 & 0.226 & 0.222 \\
\hline United States & 2.195 & 1.657 & 2.238 & 2.858 & 2.114 & 2.319 & 2.279 & 2.316 \\
\hline Canada & 0.666 & 0.572 & 0.793 & 0.925 & 0.725 & 0.928 & 0.907 & 0.883 \\
\hline United Kingdom & 1.042 & 0.707 & 0.640 & 0.836 & 0.572 & 0.661 & 0.691 & 0.670 \\
\hline Germany & 1.348 & 1.201 & 1.713 & 1.548 & 1.044 & 1.038 & 0.955 & 0.961 \\
\hline France & 0.699 & 0.654 & 0.814 & 0.829 & 0.622 & 0.635 & 0.550 & 0.562 \\
\hline Italy & 0.297 & 0.268 & 0.319 & 0.324 & 0.266 & 0.293 & 0.257 & 0.323 \\
\hline Russia & 17.454 & 7.972 & 14.841 & 22.756 & 19.196 & 12.489 & 9.332 & 3.745 \\
\hline Switzerland & 0.149 & 0.166 & 0.310 & 0.291 & 0.163 & 0.156 & 0.142 & 0.136 \\
\hline Sweden & 0.277 & 0.210 & 0.263 & 0.306 & 0.227 & 0.197 & 0.178 & 0.199 \\
\hline Spain & 0.137 & 0.125 & 0.155 & 0.139 & 0.095 & 0.124 & 0.126 & 0.122 \\
\hline Australia & 0.701 & 0.610 & 0.733 & 0.859 & 0.687 & 0.769 & 0.803 & 0.727 \\
\hline New Zealand & 0.111 & 0.076 & 0.107 & 0.115 & 0.149 & 0.110 & 0.142 & 0.135 \\
\hline
\end{tabular}




\begin{tabular}{lllllllll}
\hline \multicolumn{1}{c}{ Year } & $\mathbf{2 0 0 8}$ & $\mathbf{2 0 0 9}$ & $\mathbf{2 0 1 0}$ & $\mathbf{2 0 1 1}$ & $\mathbf{2 0 1 2}$ & $\mathbf{2 0 1 3}$ & $\mathbf{2 0 1 4}$ & $\mathbf{2 0 1 5}$ \\
\hline Peron-time (10 Thousand) & 14.370 & 12.180 & 11.330 & 13.620 & 11.510 & 10.390 & 10.790 & 11.870 \\
\hline Hong Kong & 2.450 & 0.560 & 0.790 & 1.130 & 0.780 & 0.760 & 1.190 & 1.060 \\
\hline Macao & 7.980 & 5.200 & 6.810 & 10.540 & 17.770 & 14.440 & 12.010 & 12.320 \\
\hline Taiwan & 23.464 & 11.703 & 9.703 & 9.200 & 10.437 & 17.344 & 14.767 & 12.645 \\
\hline Other & 97.930 & 55.150 & 66.310 & 81.460 & 81.560 & 75.640 & 66.140 & 60.840 \\
\hline Total & & & & & & 540 & \\
\hline
\end{tabular}

\section{THE ANALYSIS BASED ON SSM OF THE TOURIST INBOUND TOURIST SOURCE STRUCTURE IN HAINAN}

\section{A. Basic Data}

Due to the lack of national inbound tourism data in 2016, the official data of inbound tourism in 2008-2015 in the whole country and Hainan is selected, as shown in "Table I" and "Table II". It can be found in "Fig. 1" that the inbound tourism in 2008-2015 in Hainan showed large fluctuations, with periodic peaks in 2008 and 2012, and bottoms in 2009 and 2015. Most of the previous researches based on SSM (a) compared and analyzed inbound tourism data from two points of time, and lacked an analysis of the periods of process evolution. If only the data of inbound tourism in Hainan on the point of time in 2008-2015 is analyzed, it is difficult to find the process characteristics of source structure evolution. Therefore, this paper intends to subdivide the period into 2008-2009, 2009-2012, and 2012-2015, to discuss and compare the dynamic process of the source structure evolution in detail. The selection of inbound tourism sources is consistent with the national statistics, and a total of 26 sources (including Hong Kong, Macao, and Taiwan) are collected.

TABLE II. NUMBER OF TOURISTS OF INBOUND TOURISM IN CHINA FROM EACH TOURIST SOURCE IN 2008-2015

\begin{tabular}{|c|c|c|c|c|c|c|c|c|}
\hline $\begin{array}{l}\text { Year } \\
\text { Peron-time (10 thousand) }\end{array}$ & 2008 & 2009 & 2010 & 2011 & 2012 & 2013 & 2014 & 2015 \\
\hline Japan & 344.612 & 331.750 & 373.120 & 365.820 & 351.820 & 287.750 & 271.760 & 249.770 \\
\hline South Korea & 396.039 & 319.750 & 407.640 & 418.540 & 406.990 & 396.900 & 418.170 & 444.440 \\
\hline North Korea & 10.182 & 10.390 & 11.640 & 15.230 & 18.060 & 20.660 & 18.440 & 18.830 \\
\hline Mongolian & 70.527 & 57.670 & 79.440 & 99.420 & 101.050 & 105.000 & 108.270 & 101.410 \\
\hline Philippines & 79.526 & 74.890 & 82.830 & 89.430 & 96.200 & 99.670 & 96.790 & 100.400 \\
\hline Thailand & 55.428 & 54.180 & 63.550 & 60.800 & 64.760 & 65.170 & 61.310 & 64.150 \\
\hline Singapore & 87.583 & 88.950 & 100.370 & 106.300 & 102.770 & 96.660 & 97.140 & 90.530 \\
\hline Indonesia & 42.625 & 46.900 & 57.340 & 60.870 & 62.200 & 60.530 & 56.690 & 54.480 \\
\hline Malaysia & 104.049 & 105.900 & 124.520 & 124.510 & 123.550 & 120.650 & 112.960 & 107.550 \\
\hline Pakistan & 7.285 & 8.150 & 8.730 & 9.250 & 9.670 & 10.650 & 10.890 & 11.310 \\
\hline India & 43.663 & 44.890 & 54.930 & 60.650 & 61.020 & 67.670 & 70.990 & 73.050 \\
\hline United States & 178.645 & 170.980 & 200.960 & 211.610 & 211.810 & 208.530 & 209.320 & 208.580 \\
\hline Canada & 53.471 & 55.030 & 68.530 & 74.800 & 70.830 & 68.420 & 66.710 & 67.980 \\
\hline United Kingdom & 55.152 & 52.880 & 57.500 & 59.570 & 61.840 & 62.500 & 60.470 & 57.960 \\
\hline Germany & 52.886 & 51.850 & 60.860 & 63.700 & 65.960 & 64.930 & 66.260 & 62.340 \\
\hline France & 42.997 & 42.480 & 51.270 & 49.310 & 52.480 & 53.350 & 51.700 & 48.690 \\
\hline Italy & 19.436 & 19.140 & 22.920 & 23.500 & 25.200 & 25.120 & 25.310 & 24.610 \\
\hline Russia & 312.342 & 174.300 & 237.030 & 253.630 & 242.620 & 218.630 & 204.580 & 158.230 \\
\hline Switzerland & 6.341 & 6.260 & 7.430 & 7.530 & 8.280 & 8.060 & 7.950 & 7.270 \\
\hline Sweden & 13.769 & 12.580 & 15.450 & 17.010 & 17.160 & 15.900 & 14.200 & 11.840 \\
\hline Spain & 11.222 & 11.450 & 13.830 & 13.990 & 13.690 & 13.240 & 14.100 & 13.630 \\
\hline Australia & 57.153 & 56.150 & 66.130 & 72.620 & 77.430 & 72.310 & 67.210 & 63.730 \\
\hline New Zealand & 10.518 & 10.040 & 11.610 & 12.090 & 12.830 & 12.860 & 12.660 & 12.540 \\
\hline Hong Kong & 7835.013 & 7733.600 & 7932.190 & 7935.770 & 7871.300 & 7688.460 & 7613.170 & 7944.810 \\
\hline Macao & 2296.634 & 2271.840 & 2317.290 & 2369.080 & 2116.060 & 2074.030 & 2063.990 & 2288.820 \\
\hline Taiwan & 438.559 & 448.400 & 514.060 & 526.300 & 534.020 & 516.250 & 536.590 & 549.860 \\
\hline Other & 377.083 & 387.190 & 435.060 & 441.020 & 460.940 & 473.870 & 512.200 & 545.220 \\
\hline Total & 13002.739 & 12647.590 & 13376.230 & 13542.350 & 13240.540 & 12907.770 & 12849.830 & 13382.030 \\
\hline
\end{tabular}

\section{B. Analysis of Inbound Tourism in Hainan Based on SSM}

1) Analysis of source structure evolution: Based on the basic principles and models of SSM, combined with the data in "Table I" and "Table II", "Table III" is calculated. 


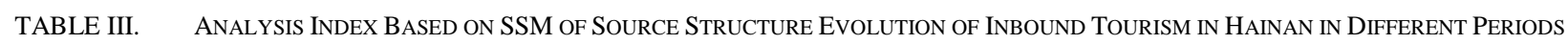

\begin{tabular}{|c|c|c|c|c|c|c|c|c|c|c|}
\hline Index & $\begin{array}{c}\mathbf{G}_{\mathbf{i}}(10 \\
\text { Thousand } \\
\text { Person-Time }) \\
\end{array}$ & $\mathbf{R}_{\mathbf{i}}(\%)$ & $\mathbf{r}_{\mathbf{i}}(\%)$ & $\begin{array}{c}\mathbf{N}_{\mathrm{i}}(10 \\
\text { Thousand } \\
\text { Person-Time })\end{array}$ & $\begin{array}{c}P_{i}(10 \text { Thousand } \\
\text { Person-Time })\end{array}$ & $\begin{array}{c}\mathbf{D}_{\mathrm{i}}(\mathbf{1 0} \\
\text { Thousand } \\
\text { Person-Time })\end{array}$ & $\begin{array}{c}\text { PD }_{\mathbf{i}}(10 \\
\text { Thousand } \\
\text { Person-Time }) \\
\end{array}$ & $\begin{array}{l}\text { Relative } \\
\text { Growth } \\
\text { Rate L }\end{array}$ & $\begin{array}{c}\text { Structure } \\
\text { Effect Index } \\
\text { W } \\
\end{array}$ & $\begin{array}{l}\text { Competitiven } \\
\text { ess Effect } \\
\text { Index U } \\
\end{array}$ \\
\hline $2008-2009$ & -42.780 & -2.731 & -43.684 & -2.675 & -7.104 & -33.001 & -40.105 & 0.579 & 0.925 & 0.626 \\
\hline $2009-2012$ & 26.410 & 4.688 & 47.888 & 2.586 & 7.661 & 16.163 & 23.824 & 1.413 & 1.133 & 1.247 \\
\hline $2012-2015$ & -20.720 & 1.069 & -25.405 & 0.589 & -6.635 & -14.675 & -21.310 & 0.738 & 0.916 & 0.806 \\
\hline $2008-2015$ & -37.090 & 2.917 & -37.874 & 2.857 & 3.655 & -43.601 & 39.946 & -0.604 & 1.036 & 0.583 \\
\hline
\end{tabular}

"Table III" shows that the inbound tourism market scale in Hainan fell by $37.874 \%$ from 2008 to 2015, while the overall growth rate of inbound tourism nationwide was $2.917 \%$, and the relative growth rate $\mathrm{L}$ was -0.604 , which fully demonstrated that the inbound tourism market in Hainan had suffered severe impact hit since the global financial crisis, and the inbound tourism market recovered slower than the overall national development rate. The total share component $\mathrm{N}_{\mathrm{i}}$ was 2.857, much higher than the total change $\mathrm{G}_{\mathrm{i}}$, indicating that the inbound tourism market in Hainan would have achieved better and faster development according to the average rate of change in national inbound tourism. The total structural shift component $\mathrm{P}_{\mathrm{i}}$ was 3.655 , and the structural effect index $\mathrm{W}$ was 1.036 $>1$, indicating that the inbound tourism market in Hainan had a prominent structural advantage, the proportion of rising and fast-growing source markets was relatively large, and the overall source market structure was good; the total competitiveness shift component $\mathrm{D}_{\mathrm{i}}$ was -43.601 , and the competitiveness effect index $U$ was $0.583<1$, indicating that the source markets in Hainan had decline severely and their competitiveness was weak.

In order to understand the periodical characteristics of evolution of the inbound tourism market structure in Hainan since the global economic crisis, the evolution of the inbound tourist source structure in 2008-2009, 2009-2012, and 20122015 is compared respectively.

- In 2008-2009, the inbound tourism market in Hainan declined by $43.684 \%$, far higher than the decline of inbound tourism nationwide $(2.731 \%)$, and the relative growth rate $\mathrm{L}$ was 0.579 , indicating that the inbound tourism market in Hainan Province was more affected by the financial crisis. The absolute value of the total share component $\mathrm{N}_{\mathrm{i}}$ was far lower than that of the total change amount $G_{i}$, indicating that the decline in the inbound tourism market in Hainan would not have shown a huge decline according to the average rate of change in the inbound tourism nationwide. The tourism industry in Hainan relied heavily on foreign countries, and was dominated by resort, while the proportion of business tourism was low. The decline in the actual purchasing power caused by the economic crisis had a greater suppression effect on the inbound tourists' willingness to travel. The total structural shift component $\mathrm{P}_{\mathrm{i}}$ for this period was -7.104, and the structural effect index $\mathrm{W}$ was $0.925<1$, indicating that the inbound tourism market structure of Hainan was poor, and shew a declining trend; the total competitiveness shift component $\mathrm{D}_{\mathrm{i}}$ was -33.001 , and the competitiveness effect index $U$ was $0.626<1$, indicating that the source markets in Hainan declined severely, and their competitiveness was weak.

- In 2009-2012, the inbound tourism market in Hainan grew by $47.888 \%$, which was far higher than the national inbound tourism growth $(4.688 \%)$. The relative growth rate $\mathrm{L}$ was $1.413>1$, which fully demonstrated that the inbound tourism market in Hainan was greatly recovery, faster than the national average. The total share component $\mathrm{N}_{\mathrm{i}}$ was lower than the total amount of change $G_{i}$, indicating that the degree of recovery of the inbound tourism market in Hainan would not have achieved the current development according to the average growth rate of inbound tourism nationwide. Comparing with 20082009 , it can be seen that the inbound tourism in Hainan was much more sensitive to economic crisis than the national average, and it could also rise quickly in the later period of recovery. Relatively speaking, the inbound tourism in Hainan was more fluctuant and vulnerable than the national average. The total structural shift component $\mathrm{P}_{\mathrm{i}}$ in this period was 7.661 and the structural effect index $\mathrm{W}$ was $1.133>1$, indicating that the proportion of rising and fastgrowing source market of inbound tourism in Hainan was relatively large, the overall source market structure was good; the total competitiveness shift component $\mathrm{D}_{\mathrm{i}}$ was 16.163 , and the competitiveness effect index $U$ was $1.247>1$, indicating that the overall growth of the source market in Hainan was significant and the comprehensive competitiveness was outstanding.

- In 2012-2015, the scale of the inbound tourism market in Hainan fell by $-25.405 \%$, while the inbound tourism nationwide grew by $1.069 \%$, and the relative growth rate $\mathrm{L}$ was $0.738<1$, indicating that the inbound tourism market in Hainan was lower than the national average. The total share component $\mathrm{N}_{\mathrm{i}}$ was higher than the total amount of change $G_{i}$, indicating that the inbound tourism in Hainan market would not have declined in this period according to the average growth rate of inbound tourism nationwide. The total structural shift component $\mathrm{P}_{\mathrm{i}}$ is -6.635 , and the structure effect index W is $0.916<1$. It can be seen that the inbound tourism market structure in Hainan is poor, showing a declining trend; the total competitiveness shift component $\mathrm{D}_{\mathrm{i}}$ was -14.675 , and the competitiveness effect index $U$ was $0.806<1$, indicating that the source markets of inbound tourism in Hainan declined severely and the competitiveness was weak. 
2) Research on the segmentation of the source market structure: In order to compare the structural changes of different tourist sources in different time periods, the analysis diagram based on share-shift is plotted according to the data in "Table III", and the inbound tourist sources are compared and classified to determine the types of the sources. Among them, the coordinate system in the analysis diagram of advantages of the source structure is established by taking the source advantage (shift component) $\mathrm{PD}_{\mathrm{ij}}$ as the abscissa, and the share component $\mathrm{N}_{\mathrm{ij}}$ as the ordinate; the coordinate system in the analysis diagram of the source structure shift component is established by taking the competition shift component $\mathrm{D}_{\mathrm{ij}}$ as the abscissa, and the structural shift component $\mathrm{P}_{\mathrm{ij}}$ as the ordinate. Both analysis diagrams are divided into eight equal sectors by two bisectors with an inclination of $45^{\circ}$, and the scattered points of each tourist source are marked in the diagram to determine the sector where the source is located in the coordinate system, judge the overall structure and competitiveness of inbound tourist sources, and identify the target source with competitive advantage [10].

a) Analysis diagram of source structure advantages: The analysis of the advantages of the inbound tourist structure in Hainan is shown in "Fig. 2". The eight sectors in the figure reflect the four different types in terms of total growth and tourist source growth advantages [6]. Among them, type I is relatively good source market, referring to growing markets with market advantages in sectors $\mathrm{S} 1$ and $\mathrm{S} 2$; type II is general source market, referring to tourist sources in sectors S3 and S4. Although markets in sector S3 have market advantages, but they are recessionary, and the markets in sector S4 are growing, but they have no market advantages. Type III is relatively poor source market, referring to the source areas in sectors S5 and S6, which sources all have a negative growth. Although the sources in sector S5 are growing, and the sources in sector S6 have regional advantages, they are not enough to eliminate the negative impact caused by market advantage or national recession; Type IV is the worst market, referring to the sources in sectors S7 and S8, which have no market advantage and show recession. "Table IV" shows the evolution of the advantages of the inbound tourist structure in Hainan in different periods.

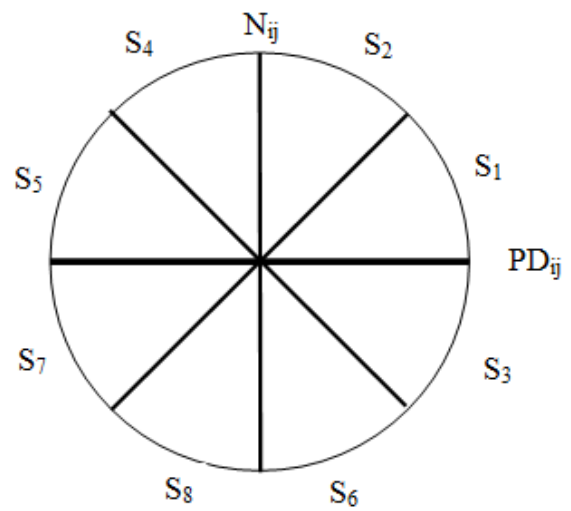

Fig. 2. Analysis diagram of advantages of inbound tourist source structure in Hainan Province.

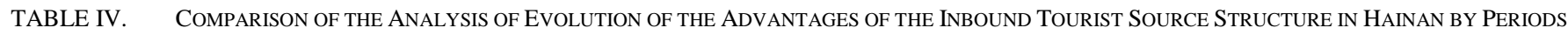

\begin{tabular}{|c|c|c|c|}
\hline \multirow{2}{*}{ Period (Years) } & \multicolumn{3}{|c|}{ Types of Advantages of Different Source Structures of Inbound Tourism In Hainan } \\
\hline & $\begin{array}{c}\text { Type I } \\
\text { (Relatively Good Source } \\
\text { Market) }\end{array}$ & $\begin{array}{c}\text { Type II } \\
\text { (General Source Market) }\end{array}$ & $\begin{array}{c}\text { Type III } \\
\text { (Relatively Poor Source Market) }\end{array}$ \\
\hline $2008-2009$ & North Korea & Mongolia, Switzerland & $\begin{array}{l}\text { Philippines, Singapore, Indonesia, Japan, South Korea, Thailand, United } \\
\text { Malaysia, Pakistan, India, Canada, States, United Kingdom, Germany, } \\
\text { Spain, Taiwan } \\
\text { France, Italy, Russia, Sweden, Australia, } \\
\text { New Zealand, Hong Kong, Macau }\end{array}$ \\
\hline 2009-2012 & $\begin{array}{l}\text { Philippines, Thailand, } \\
\text { Singapore, Indonesia, } \\
\text { Malaysia, Pakistan, India, } \\
\text { United States, Canada, } \\
\text { Russia, New Zealand, } \\
\text { Taiwan }\end{array}$ & $\begin{array}{l}\text { Mongolia, Sweden, } \\
\text { Australia, Hong Kong, } \\
\text { Macau }\end{array}$ & $\begin{array}{l}\text { Japan, South Korea, North Korea, } \\
\text { United Kingdom, Germany, } \\
\text { France, Italy, Switzerland, Spain }\end{array}$ \\
\hline $2012-2015$ & $\begin{array}{l}\text { South Korea, North } \\
\text { Korea, Mongolia, } \\
\text { Pakistan, Hong Kong }\end{array}$ & $\begin{array}{l}\text { Thailand, United States, } \\
\text { Canada, United Kingdom, } \\
\text { Italy, Spain, Australia, } \\
\text { Macau }\end{array}$ & $\begin{array}{l}\text { Japan, Singapore, Indonesia, Malaysia, } \\
\text { Germany, France, Russia, Switzerland, } \\
\text { Sweden, New Zealand }\end{array}$ \\
\hline $2008-2015$ & $\begin{array}{l}\text { Mongolia, Thailand, } \\
\text { Indonesia, Canada, New } \\
\text { Zealand, Taiwan }\end{array}$ & $\begin{array}{l}\text { Philippines, Pakistan, } \\
\text { United States, Italy, } \\
\text { Australia }\end{array}$ & $\begin{array}{l}\text { South Korea, North Korea, Japan, Russia, Sweden, Macau } \\
\text { Singapore, Malaysia, India, United } \\
\text { Kingdom, Germany, France, } \\
\text { Switzerland, Spain, Hong Kong }\end{array}$ \\
\hline
\end{tabular}

Note: There are a total of 26 tourist sources in Table IV, due to limited length, the values of $\mathrm{N}_{\mathrm{i}}, \mathrm{P}_{\mathrm{i}}$ and $\mathrm{D}_{\mathrm{i}}$ in each tourist source are no longer displayed.

The data of 2008-2015 in "Table IV" shows that Mongolia, Thailand, Indonesia, Canada, New Zealand and Taiwan were relatively good sources of the inbound tourism in Hainan in Region I; the Philippines, Pakistan, the United States, Italy and Australia were the general tourist sources in Region II; South Korea, North Korea, Singapore, Malaysia, India, the United Kingdom, Germany, France, Switzerland, Spain and Hong
Kong were the relatively poor sources; Japan, Russia, Sweden, and Macau were the worst sources. It can be seen that there were major changes in the inbound tourist source structure in Hainan during this period. Traditional sources such as Russia, Japan, Macau, South Korea, Singapore, Malaysia, Hong Kong, as well as the United Kingdom, France, Germany, Switzerland, etc. in Europe fell to relatively poor and worst sources; the 
general and relatively good sources included Taiwan, Thailand, Indonesia, the Philippines, Pakistan in Asia, as well as the United States and Canada in North America. The shrinkage of the traditional tourist sources of the inbound tourism in Hainan weakened the overall competitive advantage and slowed down the speed of development. In terms of periods, in 2008-2009, apart from North Korea, Mongolia and Switzerland, the other sources of inbound tourism in Hainan were all relatively poor or worst source markets. During the recovery period in 20092012, there was no worst source market. Japan, Korea, the United Kingdom, Germany, France and Italy turned from the worst source markets to the relatively poor source markets, while most of the other sources turned to general source markets or relatively good source markets. During this period, the advantage of the source structure of the inbound tourism in Hainan improved significantly. Compared with the previous period, the advantages of the inbound tourist source structure in Hainan declined in 2012-2015, the number of relatively good source markets decreased significantly, while the number of worst source markets increased. Apart from South Korea, Thailand, the United States, Canada, Hong Kong and Macau were relatively good or general source markets, the advantages of traditional major sources such as Japan, Russia, Singapore, Malaysia, the Philippines, Taiwan and Indonesia declined.

b) Analysis diagram of the source structure based on SSM: The analysis of the inbound tourist source structure in Hainan based on SSM is shown in "Fig. 3". In the figure, sector S1 refers to relatively good sources with good original foundation and strong competitiveness; sector S2 refers to relatively good sources with strong competitiveness and relatively good original foundation; sector S3 refers to relatively good or general sources with poor foundation but rapid development; sector S4 refers to relatively good or general sources with relatively good foundation but are declining; sector S5 refers to relatively poor sources with good foundation but poor competitiveness; sector S6 refers to relatively poor sources with poor foundation but rapid development; sectors S7 and S8 refer to the worst sources with poor foundation and weak competitiveness [10]. "Table $V^{\prime \prime}$ summarizes the evolution of shift components of the inbound tourist source structure in Hainan in different time periods.

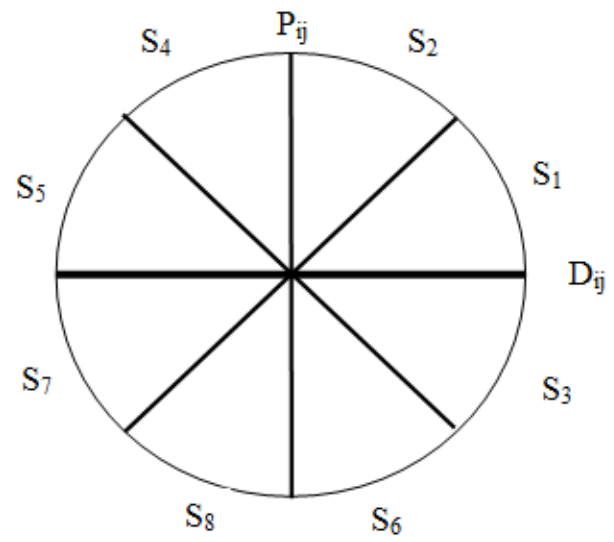

Fig. 3. Analysis diagram of shift components of the inbound tourist source structure in Hainan Province.

TABLE V. COMPARISON OF SHIFT COMPONENTS OF INBOUND TOURIST SOURCE STRUCTURE IN HAINAN BY PERIOD

\begin{tabular}{|c|c|c|c|c|c|c|c|}
\hline \multirow{3}{*}{$\begin{array}{l}\text { Source Attribution } \\
\text { Period (Years) } \\
\end{array}$} & \multicolumn{7}{|c|}{ Types of Shift of Different Source Structures of Inbound Tourism in Hainan } \\
\hline & Sector S1 & Sector S2 & Sector $\mathrm{S3}$ & Sector S4 & Sector S5 & Sector S6 & Sector S7, S8 \\
\hline & & & & & & & \\
\hline \multirow{3}{*}{ 2008-2009 } & North Korea & Mongolia & Switzerland & Philippines & $\begin{array}{l}\text { Singapore, Malaysia, } \\
\text { Canada, Spain, Hong }\end{array}$ & & $\begin{array}{l}\text { Japan, South Korea, Thailand, } \\
\text { Indonesia, Pakistan, India, }\end{array}$ \\
\hline & & & & & Kong, Macau, Taiwan & & United States, United Kingdom, \\
\hline & & & & & & & $\begin{array}{l}\text { Germany, France, Italy, Russia, } \\
\text { Sweden, Australia, New Zealand }\end{array}$ \\
\hline \multirow{5}{*}{ 2009-2012 } & Thailand, & Malaysia, & Philippines, & Canada & Japan, Korea, North & Mongolia & Hong Kong \\
\hline & Singapore, & United & Pakistan, India & & Korea, United Kingdom, & & \\
\hline & Indonesia, & States, & & & Germany, France, Italy, & & \\
\hline & Russia, New & Macau & & & Switzerland, Sweden, & & \\
\hline & Zealand, Taiwan & & & & Spain, Australia & & \\
\hline \multirow{8}{*}{$2012-2015$} & & & South Korea, North & & Taiwan & Sweden, & Japan, Philippines, Singapore, \\
\hline & & & Korea, Mongolia, & & & Macau & Indonesia, Malaysia, India, \\
\hline & & & Thailand, Pakistan, & & & & Russia, New Zealand, Germany, \\
\hline & & & United States, & & & & France, Switzerland \\
\hline & & & Canada, United & & & & \\
\hline & & & Kingdom, Italy, & & & & \\
\hline & & & Spain, Australia, & & & & \\
\hline & & & Hong Kong & & & & \\
\hline \multirow{7}{*}{$2008-2015$} & Thailand, Taiwa & nCanada, & Mongolia, & & South Korea, North & & Japan, Philippines, India, Russia, \\
\hline & & New & Indonesia, Pakistan & & Korea, Singapore, & & Sweden, Hong Kong \\
\hline & & Zealand & & & Malaysia, United States, & & \\
\hline & & & & & United Kingdom, & & \\
\hline & & & & & Germany, France, Italy, & & \\
\hline & & & & & Switzerland, Spain, & & \\
\hline & & & & & Australia, Macau & & \\
\hline
\end{tabular}

The data of 2008-2015 in "Table V" shows that only Thailand, Taiwan, Canada and New Zealand were relatively good sources in terms of competitiveness and original foundation, but the size of their sources was limited; tourist foundation of Mongolia, Indonesia and Pakistan was weak but the development was fast; South Korea, Singapore, Malaysia, 
the United States, Macau, Australia, the United Kingdom, Germany, France, Italy, Switzerland, Spain and other places had good tourist foundation, but their competitiveness was weak; the rest were the worst uncompetitive sources with weak foundation, including Russia, Japan, Hong Kong and other former major sources. The adverse impact of the global economic crisis on inbound tourism in Hainan was not eradicated, the development pace of emerging markets was limited, and the decline in the traditional major sources was not yet effectively contained. In terms of periods, in 2008-2009, only North Korea and Mongolia were sources with relatively good competitiveness and original foundation, but the scale of tourists was relatively limited; the source foundation of Switzerland was weak but the development was fast; the foundation of the Philippines was relatively good but the status of tourist source declined; Hong Kong, Macau, Taiwan, Singapore, Malaysia, Canada, Spain and other places had good tourist foundations, but their competitiveness was weak; the rest were all the worst uncompetitive sources with weak foundation. Due to the impact of the global economic crisis during this period, the market size of most of the tourist sources declined. During the recovery period of 2009-2012, sources with relatively good competitiveness and original foundation included Russia, the United States, Macau, Thailand, Singapore, Indonesia, New Zealand, Taiwan, and Malaysia; the Philippines, Pakistan, and India had weak tourist foundation but fast development, Canada's foundation was good, but its status as a tourist source declined; Japan, South Korea, North Korea, the United Kingdom, Germany, France, Italy, Switzerland, Sweden, Spain, Australia and other places had good tourist foundation, but their competitiveness was weak; the tourist foundation of Mongolia was poor but the development was fast; Hong Kong was the worst source of tourists during this period. In 2012-2015, there was basically no tourist source with relatively good competitiveness and original foundation, and the inbound tourism in Hainan once again presented a grim situation of gradual decline; South Korea, Thailand, Pakistan, the United States, Canada, the United Kingdom, Italy, Spain, Australia, and Hong Kong had poor tourist foundation but fast development; Taiwan had a good tourist foundation, but its competitiveness was weak; Macau and Sweden had a poor tourist foundations but fast developments; and rest deteriorated to the worst uncompetitive sources with poor foundation; compared to 2009-2012, the shift of the inbound tourist source structure in Hainan during this period indicated that the contribution of competitiveness and original foundation of multiple tourist sources of Hainan to the growth of inbound tourist sources of Hainan were seriously weakening, and Hainan needed to enhance the precise development of the inbound tourist source market.

\section{CONCLUSION}

In summary, the inbound tourism market of Hainan in 2008-2009 experienced a significant decline in tourist source structure and competitiveness, in which most of the tourist sources were in the relatively poor or worst types; in the market recovery period in 2009-2012, the overall source market structure of inbound tourism in Hainan was relatively good, with significant increase, and strong competitiveness. Among them, rising and fast-growing source markets accounted for a relatively high proportion. Russia, Taiwan, Macau, Singapore, Thailand, Indonesia, Malaysia and other tourist sources recovered well; however, in 2012-2015, the inbound tourism in Hainan once again entered a trough, and the overall tourist structure and competitiveness deteriorated. In that period, only sources such as Hong Kong, Macau, the United States, Canada, Thailand and South Korea maintained at a general level, and the market size of traditional tourist sources such as Russia, Japan, Singapore, Malaysia, Indonesia, and the Philippines was greatly reduced.

The fluctuation and changes of inbound tourism in Hainan since 2008 has been affected by multiple factors, and there are also great differences between different tourist sources. The inbound tourist source market in Hainan needs more effective development. First of all, it is necessary to guarantee the stability of dominant source markets, such as Hong Kong, Macau, Thailand, the United States, Canada, and Australia, and focus on stabilizing the advantages of these source markets. Secondly, it is necessary to enhance the specific development of traditional major tourist sources, grasp historical opportunities such as the "Belt and Road Initiative", ASEAN tourism cooperation, free trade zone and free trade port in Hainan, and attract traditional tourist source markets such as Russia, Japan, South Korea, Singapore, Malaysia and Indonesia thorough multi-dimensional improvements such as enriching flight routes, expanding visa on arrival and visa exemption, carrying out professional marketing and optimizing shopping tax rebates. Finally, it is necessary to continuously improve the supply of tourism services and enhance the level of internationalization. In the context of intensified competition in Southeast Asian tourist markets, slow pace of global economic development, and appreciation of the RMB exchange rate, there is a long distance between the tourist sources of Europe \& North America and Hainan. Only by creating more unique tourism products and international tourism service experience can it appeal to the European and North America tourist source markets.

\section{REFERENCES}

[1] Fang Yelin, Huang Zhenfang, Hu Zui, Li Jinglong, Liu Fajian Evolution of spatial-temporal pattern and classification of inbound tourism industry structure in Mainland China [J]. Economic Geography, 2016, 36(03): 179-185.

[2] Huang Xiujuan. Research on the Application of Market Share Analysis Method in the Selection of China's International Tourism Marketing Objectives [J]. Journal of Beijing International Studies University, 2004 (03): 97-101.

[3] Lv Shuai, Wang Yuming, Gong Wei, Cheng Yi. Analysis of source structure in tourism market based on SSM: Taking Shanghai overseas tourists market as an example [J].Tourism Tribune, 2006, (11): 60-64.

[4] Zhou Caiping. Analysis of the Resource Structure of Inbound Tourism Market Based on SSM: Taking Zhejiang Province as an Example[J].Tourism Tribune, 2008, (01): 46-51.

[5] Cui Feng, Zhao Hua. Research on the Structure of Inbound Tourism Market in Jiangsu Province Based on SSM [J]. East China Economic Management, 2008, (07): 9-13+34.

[6] Wang Li, MENG Duo. Analysis of the structure of the inbound tourist market in Liaoning province based on SSM [J]. Resource Development \& Market,2011, 27(11): 1047-1050.

[7] Shi Dan. Analysis of the evolution of the tourist source market structure based on SSM: Taking the inbound tourist source market of Jilin 
Province as an example [J]. Journal of Arid Land Resources and Environment, 2010, 24(11): 180-184.

[8] Su Peng. Research on spatial-temporal structure and optimization of inbound tourism in Hainan [D]. Hainan University, 2010.

[9] Zhao Yuesi. Analysis of the Competition Situation of the Inbound Tourist Market in Hainan Based on Pan-Pearl River Delta Regional Cooperation and Countermeasures [D]. Hainan University, 2013.

[10] Yang Airong, Leng Chuanming. Application of Shift-Share Method in Analysis of Regional Economic Structure in China [J]. Journal of Xi'an University of Arts and Sciences (Natural Science Edition), 2005, (01): 85-90. 